\title{
analisis Perilaku Komponen Sekolah Terhadap Penerapan Program Zero WASTE DI SEKOLAH
}

\author{
${ }^{1}$ Gita Prajati, ${ }^{2}$ Darwin \\ ${ }^{1,2}$ Universitas Universal, Kompleks Maha Vihara Duta Maitreya, \\ Bukit Beruntung, Sungai Panas, Batam 29456 \\ Email: ${ }^{1}$ prajati@uvers.ac.id, 1giet1103@gmail.com, ${ }^{2}$ tandarwin10@yahoo.com
}

\begin{abstract}
Zero waste is a new concept that offers answer on the matter the amount of waste that rises as a consequence of the economic growth and consumption. One way to apply zero waste concept is by reducing waste. It can be applied on all members of the community. This research's aim is to understand the behavior factors that can affect the process of zero waste in school. This research is divided into three phases. The first phase is to collect primary and secondary through observation, interview and questionnaire. While the second stage is processing datas using chi-square method. The last phase is data analysis. The result showed that for the school teachers and employees, there was only one variable was significant to the implementation of zero waste in school, which is the receiving attitude. While for the students there are three variables that were significant to the implementation of zero waste in school, which are receiving, responding and responsible attitude.
\end{abstract}

Keywords: zero waste, school, attitude

\begin{abstract}
Abstrak. Zero waste merupakan suatu konsep baru yang menawarkan jawaban atas permasalahan jumlah sampah yang meningkat akibat adanya pertumbuhan ekonomi dan konsumsi masyarakat. Salah satu cara penerapan zero waste adalah dengan cara mengurangi sampah. Cara ini bisa diterapkan di seluruh lapisan masyarakat. Penelitian ini bertujuan untuk mengetahui faktor-faktor perilaku yang dapat mempengaruhi proses penerapan zero waste di sekolah. Penelitian ini dibagi menjadi tiga tahap. Tahap pertama merupakan tahap pengumpulan data baik data primer maupun data sekunder Pengumpulan data dilakukan melalui observasi, wawancara dan penyebaran kuisioner. Sedangkan tahap kedua merupakan tahap pengolahan data. Data-data yang terkumpul diolah menggunakan metode chisquare. Kemudian tahap ketiga merupakan tahap analisa data. Hasil penelitan menunjukkn bahwa untuk kelompok guru dan pegawai sekolah, hanya ada satu variabel yang memiliki hubungan signifikan dengan terhadap pelaksanaan zero waste di sekolah, yaitu sikap menerima. Sedangkan untuk kelompok siswa sekolah ada tiga buah variabel yang memiliki hubungan signifikan dengan terhadap pelaksanaan zero waste di sekolah, yaitu sikap menerima, sikap merespon dan sikap bertanggungjawab.
\end{abstract}

Kata kunci: zero waste, sekolah, perilaku

\section{Pendahuluan}

Konsumsi yang tinggi dari masyarakat akan menaikkan jumlah sampah kota baik berupa sampah makanan, elektronik, dan kertas dengan jumlah yang sangat besar. Jika jumlah sampah yang semakin meninggi tidak diatasi dengan serius, maka dapat menimbulkan permaslahan yang cukup serius di bidang sosio-ekonomi dan lingkungan. Selain itu, eksploitasi besar-besaran yang dilakukan unuk memenuhi kebutuhan manusia juga dapat menimbulkan masalah akan 
kelangkaan SDA. Oleh karena itu, dibutuhkan suatu konsep pengelolaan sampah serta SDA yang dapat diterapkan di selurh lapisan masyarakat.

Zero waste merupakan suatu konsep perancangan dan pengelolaan produk dan sistem secara sistematik. Konsep zero waste dilakukan untuk menghindari dan mengurangi jumlah sampah dan SDA yang digunakan, serta untuk mengkonservasi dan memulihkan kembali SDA yang sudah terkena dampak oleh limbah (Zaman dan Lehmann, 2011). Dikutip dari Allen dkk. (2012), kota-kota seperti Pune, San Fransisco, Buenos Aires, Mumbai dan La Pintana telah menunjukkan kemajuan yang nyata dalam usaha pencapaian tujuan dari zero waste. Bahkan beberapa kota di dunia memiliki tujuan untuk menjadi suatu kota berkonsep zero waste. Di Indonesia sendiri beberapa lembaga dan yayasan non pemerintah dan non profit sudah melakukan pengenalan serta pelatihan mengenai zero waste. Yayasan Pengembangan Biosains dan Bioteknologi (YPPB) yang berlokasi di Kota Bandung telah melaksanakan kegiatan kampanye hidup bebas sampah. Dimana kampanye itu bertujuan untuk mengajak masyarakat khususnya ibu rumah tangga agar mau melakukan upaya pengurangan sampah dan penekanan volume sampah. Sebagian besar ibu rumah tangga menyetujui gagasan zero waste tersebut dan turut menerapkan gagasan tersebut dalam kesehariannya (Komari, 2014).

Schumpert dkk. (2012) menyatakan bahwa konsep zero waste merupakan suatu konsep berkelanjutan nyata yang dapat diterapkan di sekolah-sekolah. Program zero waste di sekolah mengajarkan kepada siswa untuk mengembangkan dan mempraktekkan pengetahuan mengenai konsep sistem berkelanjutan dengan cara mengurai produksi sampah. Sekolah merupakan kunci dari seluruh lapisan masyarakat agar konsep zero waste dapat berjalan dengan baik (Griffith dkk., 2007).

Kerja sama dari seluruh pihak sangat dibutuhkan dalam pelaksanan zero wase di sekolah. Melalui pengajaran, pelatihan dan kerja sama pelaksanaan program pengurangan sampah di sekolah dapat berjalan dengan baik (Schwarz, 2014). Nurhadyana (2012) menyimpulkan bahwa terdapat beberapa faktor yang dapat mempengaruhi perilaku siswa dalam membuang sampah. Beberapa diantaranya adalah usia, jenis kelamin, pengetahuan, sikap, ketersediaan sarana, peraturan sekolah, serta dukungan orang tua dan guru. Selain itu, Mackenzie (2010) menyatakan bahwa faktor yang dapat mempengaruhi pelaksanaan program pendidikan lingkungan di sekolah, diantaranya adalah kurangnya komitmen dari siswa dan pegawai sekolah serta kesulitan dalam mengubah kebiasaan siswa.

Penelitian Kolbe (2015) menunjukkan bahwa siswa yang memiliki pengetahuan lebih mengenai pengelolaan sampah memiliki keinginan untuk mengelola sampah dengan cara yang lebih baik, seperti daur ulang sampah. Sedangkan siswa yang memiliki tingkat pengetahuan lebih rendah membutuhkan perintah dari guru untuk melakukan daur ulang sampah. Hasil penelitian ini menunjukkan bahwa ada hubungan antara tingkat pengetahuan dan tindakan yang diambil oleh siswa terkait dengan pengelolaan sampah.

Menurut Notoadmojo (2003), perilaku manusia dibagi menjadi tiga domain utama. Ketiga domain tersebut adalah pengetahuan, sikap dan praktek atau tindakan. Oleh karena itu, penelitian ini bertujuan untuk menganalisa pengaruh perilaku (pengetahuan dan sikap) dari seluruh komponen sekolah terhadap program zero waste. Sehingga akan diperoleh domain mana yang memiliki pengaruh paling besar terhadap pelaksanaan program zero waste di sekolah.

\section{Metoda Penelitian}

Penelitian ini menggunakan lima variabel independen, yaitu pengetahuan, sikap menerima, sikap merespon, sikap menghargai dan sikap bertanggungjawab. Sedangkan untuk variabel dependennya adalah tindakan atau perilaku. Pengumpulan data sekunder dilakukan dengan cara penyebaran kuisioner dan wawancara di SMK Maitreyawira Batam. Kuisioner disebarkan kepada dua puluh lima orang responden, yang terdiri atas delapan belas orang guru dan tujuh orang pegawai sekolah. Pengolahan data secara statistik yang diujicobakan terhadap data adalah Uji Chi-square. Uji chi-square dilakukan untuk mengetahui hubungan antara suatu variabel dengan pelaksanaan program zero waste di sekolah. 


\section{Hasil dan Pembahasan}

\section{Hubungan Antara Variabel Pengetahuan dan Tindakan}

Ada empat kategori responden berdasarkan hubungan yang terjadi antara pengetahuan dan tindakan. Kategori pertama adalah responden dengan tingkat pengetahuan yang kurang dengan tindakan yang kurang mendukung pelaksanaan zero waste. Kategori kedua adalah responden dengan pengetahuan kurang tapi melakukan tindakan yang cukup mendukung pelaksanaan zero waste. bahwa responden dengan tingkat pengetahuan kurang mengenai konsep zero waste melakukan tindakan yang juga kurang mendukung pelaksanaan zero waste itu sendiri. Selanjutnya ada kategori ketiga, yaitu kategori responden dengan tingkat pengetahuan yang cukup namun melakukan tindakan yang kurang mendukung pelaksanaan zero waste. Kemudian kategori terakhir adalah kategori responden dengan tingkat pengetahuan yang cukup dan mampu melakukan tindakan yang cukup mendukung pelaksanaan zero waste.

Untuk kelompok guru dan pegawai sekolah ada sekitar 32\% responden yang masuk ke dalam ketegori pertama. Sedangkan sebanyak 32\% responden masuk ke dalam kategori terakhir. Kemudian untuk kategori kedua dan ketiga secara berturut-turut terdapat $20 \%$ dan $16 \%$ responden yang masuk ke dalam kedua kategori ini. Untuk kelompok siswa ada sekitar $12,1 \%$ responden yang masuk ke dalam kategori pertama. Hasil survei tersebut lebih baik bila dibandingkan dengan hasil survei yang dilakukan terhadap guru dan pegawai sekolah. Hal ini berkaitan dengan hasil survei yang menunjukkan bahwa lebih banyak responden siswa yang memiliki dan memahami konsep zero waste dibandingkan responden guru dan pegawai sekolah. jika responden memilki tingkat pengetahuan dan pemahaman yang cukup maka mereka akan melakukan tindakan yang mendukung pelaksanaan program zero waste.

Kemudian di kelompok siswa sekolah sebanyak 9,1\% responden masuk ke dalam kategori responden dengan tingkat pengetahuan yang cukup tetapi melakukan tindakan yang kurang mendukung pelaksanaan program zero waste. Kemudian untuk kategori ketiga, terdapat $18,2 \%$ responden yang termasuk ke dalam kategori ini. Sedangkan untuk kategori terakhir, terdapat $60,6 \%$ responden yang masuk ke dalam kategori ini. Sama halnya dengan kategori pertama, hasil survei ini lebih baik bila dibandingkan dengan hasil survei yang dilakukan terhadap guru dan pegawai sekolah.

Hasil analisis statistik untuk kelompok guru dan pegawai sekolah serta siswa sekolah menunjukkan bahwa tidak ada hubungan yang signifikan antara pengetahuan dan tindakan yang dilakukan dalam hal penerapan zero waste di sekolah.

\section{Hubungan Antara Variabel Sikap Menerima dan Tindakan}

Kelompok guru dan pegawai sekolah menunjukkan bahwa responden yang memiliki sikap negatif terhadap penerimaan penerapan zero waste melakukan tindakan yang juga kurang mendukung pelaksanaan zero waste itu sendiri. Ada sekitar $8 \%$ responden yang masuk ke dalam ketegori ini. Sedangkan sebanyak $76 \%$ responden masuk ke dalam kategori responden yang memiliki sifat positif terhadap penerimaan zero waste dan mampu melakukan tindakan yang cukup mendukung pelaksanaan program zero waste.

Untuk kelompok responden siswa sekolah, hasil analisa data menunjukkan bahwa responden yang memiliki sikap negatif terhadap penerimaan penerapan zero waste melakukan tindakan yang juga kurang mendukung pelaksanaan zero waste itu sendiri. Ada sekitar 27,3\% responden yang masuk ke dalam ketegori ini. Sedangkan sebanyak $60,6 \%$ responden masuk ke dalam kategori responden yang memiliki sifat positif terhadap penerimaan zero waste dan melakukan tindakan yang cukup mendukung pelaksanaan program zero waste.

Kemudian untuk hasil analisis statistik untuk kedua kelompok responden menyatakan bahwa sikap menerima memiliki hubungan yang signifikan terhadap tindakan yang dilakukan oleh kedua kelompok responden dalam hal penerapan zero waste di sekolah. 


\section{Hubungan Antara Variabel Sikap Merespon dan Tindakan}

Hasil penelitian menunjukkan bahwa sebanyak 50\% dari kelompok responden guru dan pegawai sekolah memiliki respon negatif terhadap peraturan dan sarana sekolah yang mendukung penerapan zero waste, melakukan tindakan yang juga kurang mendukung pelaksanaan zero waste itu sendiri. Sedangkan sebanyak $50 \%$ responden masuk ke dalam kategori responden yang memiliki respon positif terhadap peraturan dan sarana sekolah yang mendukung penerapan zero waste, tetapi melakukan tindakan yang kurang mendukung pelaksanaan program zero waste.

Kemudian untuk kelompok responden siswa sekolah, ada sekitar 30,3\% yang memiliki respon negatif terhadap peraturan dan sarana sekolah yang mendukung penerapan zero waste, melakukan tindakan yang juga kurang mendukung pelaksanaan zero waste itu sendiri. Sedangkan sebanyak 33,3\% responden masuk ke dalam kategori responden yang memiliki respon positif terhadap peraturan dan sarana sekolah yang mendukung penerapan zero waste, dan melakukan tindakan yang cukup mendukung pelaksanaan program zero waste.

Namun, untuk hasil analisa statistik terdapat perbedaan. Dimana untuk kelompok responden guru dan pegawai sekolah menunjukkan bahwa tidak ada hubungan yang signifikan antara sikap merespon dengan tindakan yang dilakukan oleh responden terhadap penerapan zero waste di sekolah. Sedangkan untuk kelompok responden siswa sekolah, hasil analisis statistik menunjukkan bahwa ada hubungan yang signifikan antara sikap merespon dengan tindakan yang dilakukan oleh responden terhadap penerapan zero waste di sekolah. Hal ini dikarenakan siswa memiliki tingkat keparuhan yang lebih tinggi dalam hal melaksanakan peraturan dibandingkan guru dan pegawai sekolah. Selain itu, hasill ini besar kemungkinan dipengaruhi oleh adanya sanksi yang diterima oleh siswa jika melanggar peraturan sekolah.

\section{Hubungan Antara Variabel Sikap Menghargai dan Tindakan}

Untuk kelompok responden guru dan pegawai sekolah terdapat sekitar 8\% yang memiliki sikap negatif mengenai dukungan lingkungan terhadap penerapan zero waste dan melakukan tindakan yang juga kurang mendukung pelaksanaan zero waste itu sendiri. Sedangkan sebanyak $60 \%$ responden masuk ke dalam kategori responden yang memiliki sikap positif mengenai dukungan lingkungan terhadap penerapan zero waste dan melakukan tindakan yang cukup mendukung pelaksanaan program zero waste.

Hasil penelitian untuk kelompok responden siswa sekolah menunjukkan bahwa terdapat sekitar 18,2\% responden yang memiliki sikap negatif mengenai dukungan lingkungan terhadap penerapan zero waste dan melakukan tindakan yang juga kurang mendukung pelaksanaan zero waste itu sendiri. Sedangkan sebanyak 36,4\% responden masuk ke dalam kategori responden yang memiliki sikap positif mengenai dukungan lingkungan terhadap penerapan zero waste, dan melakukan tindakan yang cukup mendukung pelaksanaan program zero waste.

Untuk hasil analisa statistik, kedua kelompok respondek menunjukkan hasil yang sama, yaitu tidak ada hubungan yang signifikan antara sikap menghargai dengan tindakan. Dengan kata lain sikap menghargai tidak memiliki hubungan yang signifikan dengan pelaksanaan zero waste di sekolah.

\section{Hubungan Antara Variabel Sikap Bertanggungjawab dan Tindakan}

Ada sekitar $4 \%$ dari kelompok responden guru dan pegawai sekolah yang memiliki sikap negatif mengenai tanggung jawab terhadap penerapan zero waste dan melakukan tindakan yang juga kurang mendukung pelaksanaan zero waste itu sendiri. yang masuk ke dalam ketegori ini. Sedangkan sebanyak $76 \%$ responden masuk ke dalam kategori responden yang memiliki sikap positif mengenai tanggung jawab terhadap penerapan zero waste dan melakukan tindakan yang cukup mendukung pelaksanaan program zero waste.

Kelompok responden siswa sekolah yang memiliki sikap negatif mengenai tanggung jawab terhadap penerapan zero waste dan melakukan tindakan yang juga kurang mendukung pelaksanaan zero waste itu sendiri, ada sekitar $18,2 \%$ responden. Sedangkan sebanyak $54,5 \%$ 
responden masuk ke dalam kategori responden yang memiliki sikap positif mengenai tanggung jawab terhadap penerapan zero waste, dan melakukan tindakan yang cukup mendukung pelaksanaan program zero waste.

Terdapat perbedaan mengenai hasil analisa statistik dari kedua kelompok responden. Kelompok responden guru sekolah dan pegawai sekolah menunjukkan bahwa tidak ada hubungan yang signifika antara sikap menghargai dengan pelaksanaan zero waste di skeolah sedangkan untuk kelompk responden siswa sekolah, terdapat hubungan yang signifikan antara sikap bertanggungjawab dengan tindakan. Dengan kata lain sikap menghargai tidak memiliki hubungan yang signifikan dengan pelaksanaan zero waste di sekolah.

\section{Kesimpulan}

Untuk kelompok responden guru dan pegawai sekolah, variabel sikap menerima merupakan variabel yang memilki pengaruh yang signifikan terhadap tindakan dalam hal penerapan zero waste di sekolah. sedangkan untuk kelompok siswa sekolah ada tiga buah variabel yang memiliki pengaruh yang signifikan terhadap tindakan dalam hal penerapan zero waste di sekolah yaitu skap menerima, merespon dan menghargai.

\section{Ucapan Terima Kasih}

Ucapan terima kasih diberikan kepada SMK Maitreyawira Batam.

\section{Daftar pustaka}

Allen, C., Gokaldas, V., Larracas, A., Minot, L.A., Morin, M., Tangri, N., Tyler, B. dan Walker, B., On The Road to Zero waste Success es and Less ons from around the World, GAIA Press. 2012.

Griffiths, M., Richards, M. dan Winters, B., How to reduce, reuse and recycle waste in schools. http://www.sustainability.vic.gov.au/services-and-advice/schools/resources/waste-moduleresources. 2007.

Kolbe, K. D., Knowledge, attitudes and behaviour regarding waste management in a grammar and a comprehensive school in england-results from a school questionnaire, Journal of Teacher Education for Sustainability, Vol. 17 No. 1, p58-71. 2015.

Komari, A. S., Sikap Ibu Rumah Tangga Terhadap Penerapan Program Zero waste Lifestyle di Kelurahan Sukaluyu Kota Bandung (Studi Deskriptif Terhadap Anggota Yayasan Pengembangan Biosains dan Bioteknologi Bandung dengan Latar Belakang Status Sosial Ekonomi Berbeda), Fakultas Ilmu Pendidikan Universitas Pendidikan Indonesia. 2014.

Mackenzie, A. C., Australian waste wise schools program: its past, present, and future, The Journal Of Environmental Education, Vol. 41 No. 3, p165-178. 2010.

Notoadmojo, S., Pengantar Pendidikan Kesehatan dan Ilmu Perilaku, Rineka Cipta, Jakarta. 2003.

Nurhadyana, I., Faktor-Faktor yang Berhubungan dengan Perilaku Membuang Sampah pada Siswa Sekolah Dasar Negeri (SDN) di Kecamatan Bantar Gebang, Tahun 2012, FKM, UI. 2012.

Schwarz, S. F., Cities In Transition Towards Zero waste: A Case Study Of Aalborg Municipality, Master Theses Faculty of Engineering and Science Department of Development and Planning, Aalborg University. 2014.

Schumpert, Kary, Dietz dan Cyndra., Zero waste: a realistic sustainability program for schools, School Business Affairs, Vol. 78 No. 2, p14-17. 2012.

Zaman, A. U. dan S. Lehmann., Challenges and opportunities in transforming a city into a zero waste city, Challenges, Vol. 2, p73-93. 2011. 